\title{
SUCOS DO BEM: O DESAFIO DE CRESCER COM A FRUTA NA CAIXINHA
}

DANiela Abrantes Ferreira - dabrantes@ uol.com.br

Faculdade de Administração da Universidade Federal do Rio de Janeiro, Rio de Janeiro - RJ, Brasil

LUCELENA AbRANTES FERREIRA - lucelena@terra.com.br

Ibmec/RJ, Rio de Janeiro - RJ, Brasil

VERÔNICA FEDER MAYER - vmayer@ gmail.com

Universidade Federal Fluminense, Rio de Janeiro - RJ, Brasil

Submetido em 26/10/2011, aceito para publicação em 20/03/2012

No início de 2010, a economia brasileira parecia recuperada dos efeitos da crise mundial de dois anos atrás. Pequenos empreendedores animavam-se com as oportunidades que vislumbravam num mercado cada vez mais promissor. Nesse contexto, o jovem Marcos Leta refletia sobre o breve histórico de sua empresa fabricante de sucos naturais e seus desafios futuros. Ao olhar para o pequeno quadro afixado na parede de entrada do seu escritório - uma gravata emoldurada, lembrança dos tempos em que trabalhava num banco de investimento - refletia que fazia menos de três anos que iniciara sua grande aventura como empreendedor. No início, tinha basicamente uma ideia na cabeça, algum capital e muita vontade de aprender. Mas, três anos depois, pensava nas oportunidades de crescimento de sua empresa. Seu grande desafio era conseguir crescer sem perder o que, para ele, era a principal razão do sucesso da Sucos do bem: a relação de confiança e a proximidade da marca com seus consumidores.

\section{O nascimento de uma ideia}

A Sucos do bem foi pensada muito antes de sua fundação. Desde a época em que cursava a faculdade de Administração, Marcos Leta já sonhava em empreender, e refletia sobre a tendência das pessoas em buscar uma alimentação mais saudável. Chegou a cogitar abrir um quiosque de lanches saudáveis no campus da faculdade, mas a ideia não foi adiante. Seu sonho acabou sendo adiado por alguns anos, pois Marcos começou a estagiar no mercado financeiro. Seu primeiro estágio foi em uma corretora de valores, e o segundo, em um banco de investimento.

Em meados de 2006, voltando do trabalho à noite, Marcos resolveu parar para lanchar em uma das muitas lojas de sucos naturais existentes na Zona Sul do Rio de Janeiro. Fazia isso com certa frequência, mas, naquela noite, ao afrouxar a gravata e saborear seu suco, pensou em como seria bom se as pessoas pudessem ter o prazer de tomar aquele suco de frutas tão gostoso e saudável 
em qualquer lugar. A partir dessa noite, uma pergunta não lhe saía da cabeça: seria possível "engarrafar" uma loja de sucos naturais?

No fim de 2006, ao terminar a faculdade, muitos questionamentos e uma certeza: aposentar definitivamente a gravata. Marcos pediu demissão do banco de investimento e resolveu viajar durante dois meses pela Europa e pelos Estados Unidos, a fim de estudar a melhor forma de colocar sua ideia em prática. Visitou diversas empresas de bebidas, priorizando aquelas que fabricavam sucos de frutas. Conversou com profissionais de muitas áreas, especialmente engenheiros de alimentos, buscando aprender tudo o que podia sobre as mais novas tecnologias de fabricação, conservação e engarrafamento de suco natural. Ouviu de muitas pessoas como seria impossível embalar sucos sem conservantes e sem aromatizantes. Descobriu que, na Europa e nos Estados Unidos, o mais próximo que se tinha de suco natural engarrafado era uma mistura de suco concentrado com o sumo da fruta propriamente, levando-se em conta o desafio de se conseguir frutas frescas nesses países. Além disso, a validade desses sucos variava entre 10 e 14 dias. "No Brasil, eu dou um chute na moita e cai laranja!" - pensou Marcos. Ele estava certo de que poderia fazer o verdadeiro suco natural de fruta, para um consumidor ávido por consumir algo saudável e gostoso ao mesmo tempo.

Marcos voltou ao Brasil no início de 2007. Na bagagem, trouxe muitas informações e uma enorme motivação para começar. Vendeu seu carro e seu apartamento, e investiu na compra de duas máquinas de processamento e esterilização de frutas. Nascia aí a Sucos do bem.

\section{Começando a fazer sucos}

Após a compra das máquinas, a próxima etapa foi encontrar os parceiros de produção de frutas e de embalagem. A Sucos do bem fez, então, parceria com duas fazendas, localizadas no Estado do Rio de Janeiro, e, em cada uma delas, foi colocada uma máquina de processamento e esterilização de frutas. Essas fazendas foram escolhidas levando-se em conta a qualidade de suas safras e também o seu potencial de produção. O desafio foi buscar fazendas que pudessem, inicialmente, fornecer quantidades pequenas de frutas, mas que tivessem capacidade de um fornecimento maior no futuro. A figura no Anexo 1 ilustra o processo de fabricação dos Sucos do bem. Apesar de o maquinário ficar nas fazendas, a operação da fabricação dos sucos era inteiramente realizada por funcionários da Sucos do bem.

A grande diferença entre o processo de fabricação dos sucos do bem e o dos outros sucos comercializados é que estes últimos são, em sua maioria, feitos a partir de um concentrado de fruta, obtido colocando-se a polpa das frutas para ferver a $180^{\circ} \mathrm{C}$ durante cerca de 7 horas. Entretanto, ao ser transformada em concentrado, a fruta perde, além da água, a maior parte de suas vitaminas e de seus nutrientes. Esse concentrado é, geralmente, misturado a aromas artificiais, conservantes, goma para deixar o suco mais espesso e, em alguns casos, açúcar ou adoçante artificial.

A Sucos do bem faz o controle da qualidade das frutas usadas na fabricação de seus sucos dentro das próprias fazendas parceiras. Trata-se de uma etapa importante na produção, na qual se avalia o aspecto, o nível de maturidade e a doçura das frutas. A empresa também gerencia a logística de levar o suco já pronto à fábrica de embalagem (onde os produtos são embalados), desta para um armazém localizado na periferia do Rio de Janeiro e, finalmente, de lá para os varejistas.

A parceria com os varejistas também foi fundamental para a empresa. Inicialmente, Marcos conseguiu convencer uma grande rede de supermercados carioca a realizar um teste cego (isto é, sem identificação de marcas) de sabor com cinco de seus diretores, usando o suco do bem e outras quatro 
marcas concorrentes. $\mathrm{O}$ suco do bem foi preferido por quatro dos cinco diretores, e então aprovado para ser colocado à venda nessa rede de supermercados, atuante principalmente nas Zonas Sul e Oeste do Rio de Janeiro. Contribuiu também para isso o fato de a Coca-Cola estar comprando a marca de sucos líder de mercado, Del Valle, acumulando, assim, diversas marcas de sucos e, portanto, um grande poder de barganha nesse mercado - o que não era interessante para os varejistas.

Mas esse início não foi muito fácil para a Sucos do bem. Os sucos eram embalados em garrafinhas PET, e sua validade era de 15 dias. Como o produto chegava ao ponto de venda cerca de 10 dias após a sua fabricação, sobravam apenas 5 dias para a venda. Como resultado, havia muitas devoluções. "Perdi muito dinheiro" - lembra Marcos - "mas pensei: ou vou ficar brincando de fazer suco ou vou ser uma das maiores indústrias de sucos no Brasil".

Em 2008, a história do jovem empreendedor que acreditava poder produzir sucos de frutas unindo saúde e sabor começou a chamar a atenção da imprensa, e algumas matérias sobre a Sucos do bem saíram em jornais e revistas de grande circulação. A história da pequena empresa que fabricava sucos $100 \%$ naturais parecia interessar ao público. Mas também gerou interesse em uma grande empresa fabricante de embalagens - a Tetra Pak - que resolveu procurar a Sucos do bem.

A embalagem Tetra Pak é composta de camadas de plástico, alumínio e papel, e tinha condições de oferecer ao suco do bem uma validade bem maior do que os 15 dias que este tinha à época. Além disso, 75\% do papel utilizado vinham de árvores reflorestadas e a caixinha Tetra Pak era $100 \%$ reciclável, o que condizia com a postura de responsabilidade socioambiental da Sucos do bem. Parecia uma oferta tentadora, mas, para Marcos, havia uma condição importante: "precisávamos manter a mesma qualidade e sabor do produto que tínhamos". Foram oito meses de testes até que se conseguisse chegar a uma embalagem ideal, capaz de preservar a qualidade e o sabor original das frutas usadas nos sucos. Em janeiro de 2009, os sucos do bem passaram a ser embalados em caixinhas Tetra Pak, com validade de 4 meses.

De janeiro a outubro de 2009, os sucos do bem estavam em 30 pontos de venda. Em outubro, uma grande distribuidora, responsável pela distribuição de alimentos e bebidas de grandes marcas, como Nestlé e Red Bull, conheceu a Sucos do bem. Em parceria com essa distribuidora, a empresa aumentou sua presença em pontos de venda significativamente, passando a figurar em 600 PDVs no Rio de Janeiro, no fim de 2009.

\section{A cultura da empresa}

O negócio da Sucos do bem era definido em três dimensões: desenvolvimento de sucos de frutas naturais, desenvolvimento de marca e relacionamento com o cliente.

Todos os funcionários, ao entrar para a empresa, tinham que emoldurar algum objeto que significasse algo a ser esquecido, deixado para trás - a começar pelo próprio fundador, que emoldurou sua gravata dos tempos de banco de investimento. Na parede de entrada do escritório, ficavam esses pequenos quadros, contendo objetos como, por exemplo, uma caixa de curativos band-aid (de uma funcionária que queria se esquecer do quanto andar de sapato de salto alto nas ruas do Centro do Rio machucava seus pés). Para os funcionários, esses quadros simbolizavam a cultura da Sucos do bem, que também era retratada no texto sobre a filosofia da empresa, presente em seu site (www.dobem.com, acesso em 01/03/2010):

Nós da do bem ${ }^{\mathrm{TM}}$ temos uma filosofia simples: fazer as melhores bebidas naturais do mundo (sem contar a que sua mãe fazia quando você era pequeno). 
Nossa paixão é a busca incansável pelos melhores ingredientes $100 \%$ verdadeiros. Desde a fruta fresca, ao processo de fazer o suco, passando pela gentil pasteurização e pela embalagem consciente, a do bem ${ }^{\mathrm{TM}}$ respeita ao máximo o direito de você beber o que é puro.

Além disso, acreditamos que podemos ter uma relação mais direta com as pessoas. Tratar você como tratamos nossos amigos e parentes. Menos empresa e mais família. Exatamente isso: uma família. Sem e-mails automáticos, sem vozes digitalizadas no telefone, nem respostas prontas. Porque sentimos que nosso mundo está precisando disso. Afeto e transparência. Ciência a serviço do natural. Mais respeito à natureza e ao ser humano.

O relacionamento direto entre a diretoria e os funcionários, e entre a empresa e seus clientes, era um dos aspectos mais importantes na cultura da Sucos do bem. Havia vários canais de comunicação à disposição dos consumidores, e os que entravam em contato com a empresa eram sempre atendidos de maneira individualizada. Essa postura surgiu de uma experiência de Marcos. Antes mesmo de a Sucos do bem começar a operar, ele enviou e-mails para grandes empresas fabricantes de alimentos, e recebeu, de todas elas, respostas automáticas e impessoais. Decidiu então que, na Sucos do bem, isso seria diferente: "Há clientes que são verdadeiros fãs da do bem, e alguns nem são do Rio, ou seja, nem consomem o nosso produto ainda! Retribuímos esse carinho com atenção individualizada."

\section{Marketing}

O posicionamento da Sucos do bem é "fazer bebidas verdadeiras que proporcionam um momento divertido para pessoas jovens de espírito". As embalagens têm cores fortes, desenhos e textos diferentes dos tradicionais encontrados nas embalagens de outras bebidas (figura no Anexo 2). Por exemplo, próximo ao orifício de se inserir o canudo, em vez do tradicional texto "fure aqui" está escrito "vai com tudo!".

Além disso, a história da empresa está impressa nas embalagens de 1 litro, em um texto que reflete o posicionamento da marca:

\section{Uma história do bem ou como enquadramos nossas gravatas}

Nos dias de hoje, parece que tudo se resume a trabalhar 25 horas por dia, chegar tarde em casa e pedir uma pizza. Tudo bem, nós reconhecemos que é preciso ralar mesmo e que, às vezes, fica muito difícil aproveitar as coisas boas da vida. Foi num dia corrido assim como qualquer outro, depois de beber um suco na nossa casa de sucos predileta no Rio de Janeiro, que tivemos a ideia de fazer uma empresa de bebidas legais e gostosas. Assim nasceu a do bemTM. Uma empresa que deixou a mesmice de lado por acreditar que a vida pode ser mais leve e bem-humorada, com uma relação mais direta com as pessoas, com a natureza e com o mundo.

Em busca de bebidas saborosas e naturais a gente não mistura nossas frutas com nomes estranhos. Corantes, acidulantes e conservadores não entram em nossas caixinhas.

Diferentemente do que acontece com a maioria das embalagens de sucos, os sucos do bem não trazem fotografias de frutas na embalagem. Segundo Marcos, "as frutas têm que estar dentro da embalagem e não fora dela. A embalagem é parte da experiência divertida de consumo do suco do bem". A logomarca é uma pequena asa, em uma alusão aos conceitos de liberdade e pureza.

A ideia é que as pessoas pudessem beber algo gostoso e saudável, mas sem aquela seriedade característica de diversos alimentos que estão vinculados ao cuidado com saúde. Nas palavras de Marcos: "A pessoa está cheia de coisas para resolver, em um dia confuso, de repente para um minutinho, pega um suco do bem e dá um sorriso no meio da tarde. Não podemos lutar contra a falta 
de tempo, que é uma realidade nos nossos dias, mas podemos proporcionar às pessoas esses pequenos momentos de descontração e prazer".

Como tornar esse posicionamento conhecido para o público? "Não tenho pressa", diz Marcos, "e não acredito em propaganda tradicional". O marketing da Sucos do bem é bastante focado em redes sociais, com uso do twitter, facebook e orkut (cujas referências de localização estão destacadas nas embalagens dos produtos). Em 2009, a empresa produziu dois vídeos, que foram colocados no site de vídeos youtube, tendo um deles atingido a marca de meio milhão de acessos (ver http://tiny.cc/gvcasos_sucos). Os vídeos mostravam as mãos de uma pessoa brincando de fazer música com objetos de uma bandeja de café da manhã e de uma mesa de escritório, respectivamente, enquanto as frutas se transformavam em caixinhas de sucos do bem. O objetivo dos vídeos era reforçar o conceito de que, já que o suco natural da fruta vinha pronto na caixinha, há coisas mais divertidas que podem ser feitas com as mãos durante o café da manhã ou o horário do lanche no trabalho.

No fim de 2009, foram realizadas algumas ações de degustação nos pontos de venda e também nas praias do Rio de Janeiro, usando o "frutomóvel”, um carro personalizado com as asinhas da marca Sucos do bem (figura no Anexo 3).

\section{Os produtos}

No início de 2010, a empresa possuía em sua linha apenas sucos, que vinham em dois tamanhos de embalagem: $200 \mathrm{ml}$ e 1 litro. Os sabores eram: laranja; limonada; misto de açaí, morango, maçã e guaraná; e misto de mamão, laranja, maçã e banana. A cada sabor correspondia uma espécie de slogan próprio, com dizeres divertidos, como mostra a figura no Anexo 4. Havia, entretanto, a ideia de se lançar novos sabores de sucos e até outros tipos de bebidas. A empresa possuía uma área de Desenvolvimento de Novos Produtos, responsável por pesquisar novos sabores e mixes de frutas.

\section{A concorrência}

Em 2010, o mercado de sucos no Brasil movimentava cerca de $\mathrm{R} \$ 2$ bilhões por ano. $\mathrm{O}$ crescimento nas vendas havia sido de $16 \%$, de 2009 em comparação com o ano anterior. Esse crescimento ocorreu, em parte, devido ao fato de que alguns consumidores vinham abandonando o consumo de refrigerantes em prol de bebidas consideradas mais saudáveis. O mercado de sucos ficou com uma fatia de 17\% dos 53,8 bilhões de litros de bebidas não alcoólicas (sucos, refrigerantes, chás, águas com sabor, bebidas isotônicas e outras) vendidos em $2009^{1}$.

O mercado brasileiro de sucos pode ser dividido em três macrocategorias: refrescos, néctares e sucos integrais, resumidas na figura no Anexo 5. Os refrescos contêm no máximo $10 \%$ de suco de fruta, já os néctares contêm cerca de $30 \%$ de suco de fruta - ambos precisam ser misturados com água e adoçados. Já os sucos integrais são compostos basicamente por suco de fruta, sem adição de açúcar ou água - o Suco do bem faz parte desta última categoria. Marcos Leta ressalta: "Ele é o único suco em caixinha que contém $100 \%$ fruta do mercado brasileiro, enquanto outros players adicionam água, açúcar e conservantes". Os néctares são vendidos sob a forma de sucos concentrados (aqueles que o próprio consumidor mistura com água e adoça) e sucos prontos para beber, e os sucos integrais são vendidos apenas sob a forma de sucos prontos.

\footnotetext{
1 Associação Brasileira das Indústrias de Refrigerantes e de Bebidas Não-Alcoólicas. Disponível em: http://www.abir.org.br/article.php3?id_article=4180. Acesso em $1^{\circ} .3 .2010$.
} 
Em 2010, o principal player no mercado de sucos prontos era a Coca-Cola Company, líder também no mercado de refrigerantes, que fez algumas aquisições importantes no mercado brasileiro de sucos prontos. Em 2005, a Coca-Cola comprou a marca Sucos Mais e, em 2006, comprou a marca líder Del Valle. Em julho de 2009, a empresa fundiu as duas marcas, criando a Del Valle Mais, com o slogan "Ficou mais fácil viver com qualidade". A figura no Anexo 6 mostra a participação das principais marcas de sucos prontos no mercado brasileiro.

A Sucos do bem, comercializando cerca de 1.000.000 litros de sucos no início de 2010, ainda não tinha uma participação significativa nesse mercado. A tabela no Anexo 7 traz uma comparação entre os quatro principais players do mercado e os Sucos do bem, levando-se em conta o sabor laranja, comum a todas as marcas aqui consideradas.

\section{Subindo os próximos degraus}

Olhando para trás, Marcos tinha a sensação de que muito tempo havia se passado desde aquele início de 2007, quando a Sucos do bem havia se tornado uma realidade, e sentia-se bastante satisfeito com o que conquistara: "O que me deixa com mais vontade de crescer é a relação que conseguimos construir com nossos consumidores. Eles se sentem como parte da família e é isso que no final do dia vale a pena pra mim, ter esse contato direto com as pessoas, fazer um grupo de jovens cansados da mesmice acreditar que podem, junto conosco, mudar o mundo das bebidas". Mas ele ainda refletia sobre a necessidade de reforçar o posicionamento da Sucos do bem: "Temos que conseguir mostrar mais os benefícios reais dos nossos produtos. Falar mais desses benefícios e não apenas da marca e do fato de sermos uma empresa diferente".

Era preciso pensar à frente. A valorização de produtos saudáveis e de empresas socialmente responsáveis pelo consumidor se desenhava como uma oportunidade cada vez mais nítida. Um dos planos para 2010 era expandir a distribuição para outros Estados, ampliando o mercado para além do Rio de Janeiro. Estavam também montando um Conselho Consultivo para a empresa, a fim de profissionalizar o negócio: "Até agora, subi pequenos degraus. Para dar o próximo passo, sei que o degrau será muito maior”. O tempo parecia curto e as dúvidas não eram poucas: ao entrar em novos mercados - incluindo São Paulo, o maior do País - deveria modificar a parceria com as fazendas produtoras e o processo de fabricação dos sucos? Como ampliar a base de consumidores dispostos a pagar até $40 \%$ a mais pelos Sucos do bem, mantendo uma relação individualizada e próxima com cada um?

Sabendo que deveria estar com seu planejamento pronto para ser implementado em cerca de três meses, Marcos refletia: "Como dar esse próximo passo, fazendo crescer a Sucos do bem, mas mantendo a relação de confiança e proximidade da marca com seus consumidores?" 
Anexo 1

Processo de fabricação dos Sucos do bem

\section{Colheita das frutas}

\section{Controle de qualidade}

Processamento e esterilização
Embalagem dos sucos

Anexo 2

Embalagens dos Sucos do bem

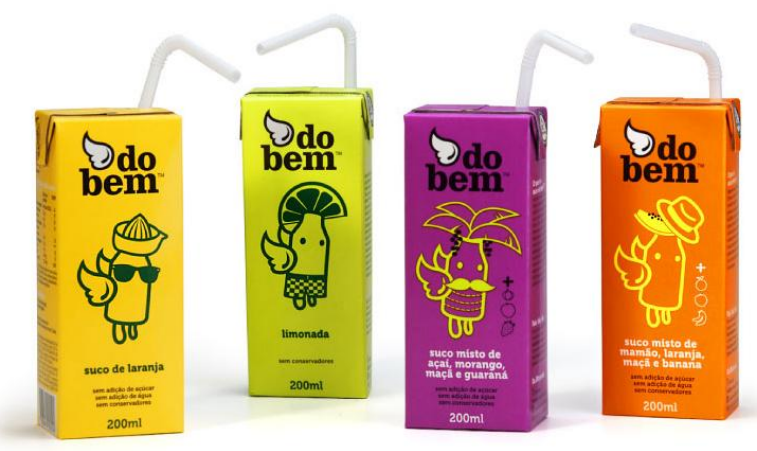

Fonte: www.dobem.com. Acesso em 1 1 .3.2010

\section{Anexo 3}

Frutomóvel

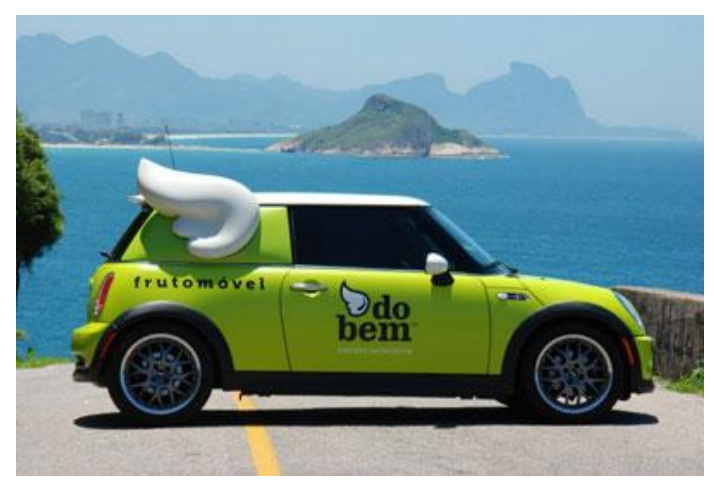

Fonte: www.dobem.com. Acesso em 1º.3.2010 


\section{Anexo 4}

Sabores e slogans dos Sucos do bem

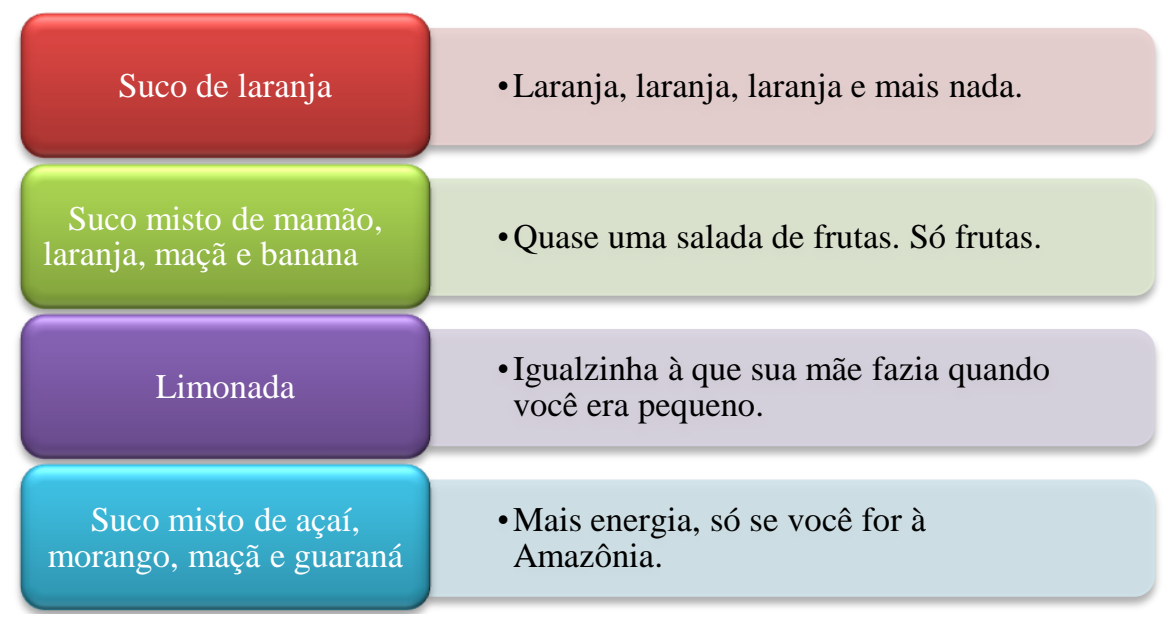

Fonte: www.dobem.com. Acesso em 1º.3.2010

\section{Anexo 5 \\ Categorias de mercado no Brasil}
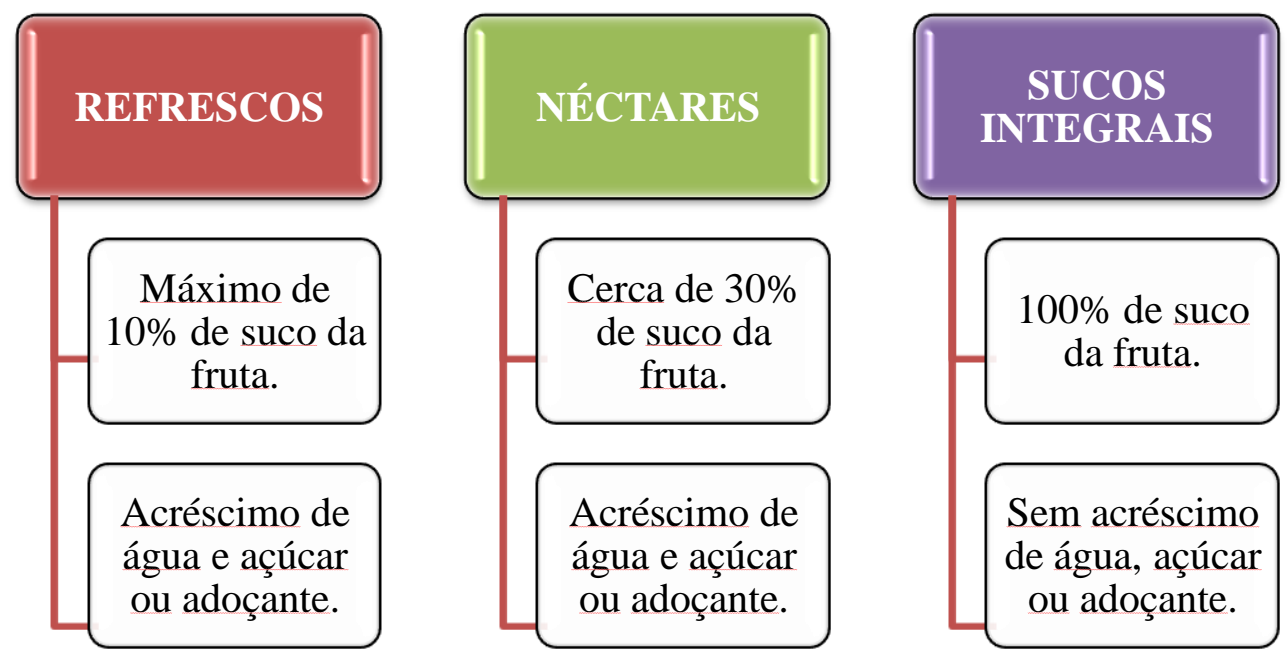


\section{Anexo 6}

Participação das principais marcas de sucos prontos no mercado

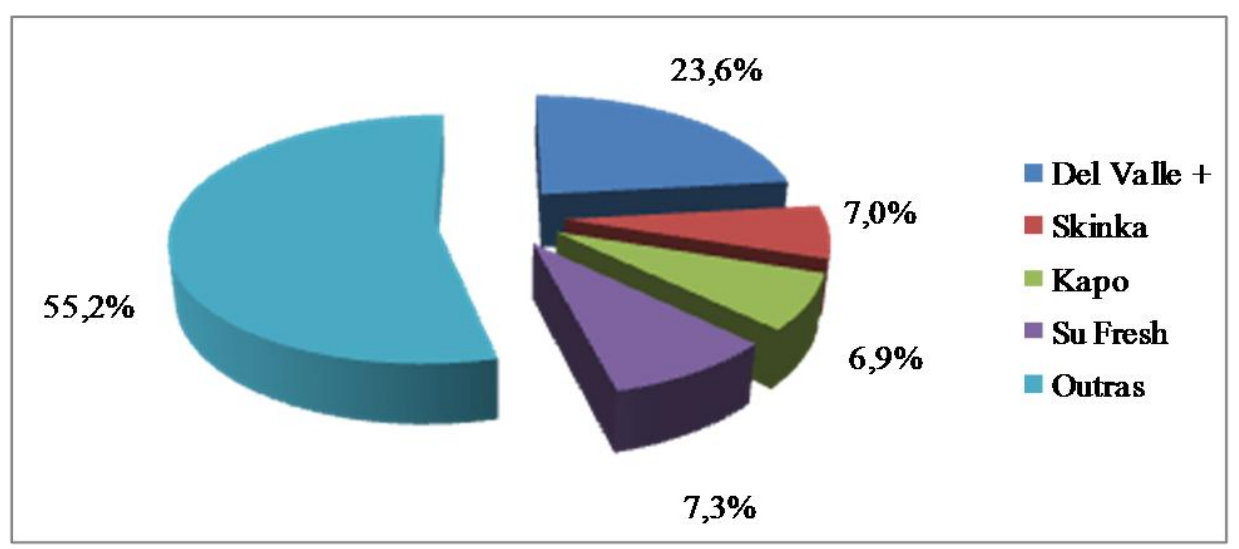

Fonte: Associação Brasileira das Indústrias de Refrigerantes e de Bebidas Não-Alcoólicas. Disponível em: http://www.abir.org.br/article.php3?id_article=4180. Acesso em 1º.3.2010.

\section{Anexo 7}

\section{Comparação de preços de sucos de laranja (em R\$)}

\begin{tabular}{|l|c|c|}
\hline & $200 \mathrm{ml}$ & 1 litro \\
\hline Sucos do bem & 2,59 & 6,99 \\
\hline Del Valle Mais & 1,79 & 4,99 \\
\hline Skinka $^{\text {a }}$ & 0,89 & - \\
\hline Kapo & 1,09 & - \\
\hline Su Fresh & - & 4,98 \\
\hline
\end{tabular}

Fonte: Pesquisa feita em duas grandes redes de supermercados da cidade do Rio de Janeiro entre os dias $1^{\circ}$ e 10 de março de 2010

a Para a marca Skinka foi considerado o sabor "frutas cítricas", visto que o sabor laranja não existe. 